\title{
Method for Calculating the Feed Water Replenishment Parameters under Electrolysis Process in Electrolyzer
}

\author{
Victor Solovey, Mykola Zipunnikov*, Vitaliy Semikin \\ A.M. Pidhorny Institute of Mechanical Engineering Problems of NASU, 2/10, Pozharsky str., 61046, \\ Kharkiv, Ukraine \\ zipunnikovnn@ukr.net
}

Keywords: water electrolysis, electrolyte, alkali concentration, electrical conductivity.

The article proposes a method for calculating parameters of feed water replenishment in an alkaline electrolyzer, taking into account the given alkali concentrations and the actual electrolyte consumption. The analysis of the electrolyte specific electrical conductivity under electrolysis process is carried out. Recommendations are given for increasing the water electrolysis process efficiency by reducing energy consumption when ensuring the optimal specific electrical electrolyte conductivity at a variable alkali concentration. One of the possible algorithms is presented for calculating electrolyzer parameters to ensure its specified operational characteristics under process of hydrogen and oxygen generation.

\section{Introduction}

The alkaline electrolytes, namely, aqueous solutions of the potassium hydroxide $(\mathrm{KOH})$ or sodium hydroxide $(\mathrm{NaOH})$ are used for generating hydrogen and oxygen under industrial water electrolysis processes.

These electrolytes meet the criteria of availability, low cost, low aggressiveness, and high electrical conductivity providing the possibility for reducing voltage losses to overcome the ohmic resistance of the electrolyte in the cell [1-15]. Aqueous solutions of some salts and acidic electrolytes are sometimes used to carry out the special water electrolysis processes (in the area of measuring equipment).
Three water electrolysis technologies are exists: Alkaline Electrolysis Cells (AEC), Proton Exchange Membrane Electrolysis Cells (PEMEC) and Solid Oxide Electrolysis Cells (SOEC). AEC is the incumbent water electrolysis technology and widely used for large-scale industrial applications. AEC systems are readily available, durable and exhibit relatively low capital cost due to the avoidance of noble metals [1]. Water electrolysis is the most promising method for efficient production of high purity hydrogen (and oxygen), while the required power input for the electrolysis process can be provided by renewable sources (e.g. solar or wind) [2]. 
Despite the alkaline electrolyzer design variety, some general patterns can be identified to determine the possible technical solutions improving the operation parameters of the electrolyzers requiring periodic water addition.

Only water is consumed from the electrolyte under process of hydrogen and oxygen generation by water electrolysis whereas alkali contained in the solution is used only for ions transferring. So, it needs to replenish water into an electrolyzer periodically. The necessity for water replenishment is occurred when the limited electrolyte volume becomes minimal.

To have a high efficiency water electrolysis it is very important ensuring the optimal range of changes of alkali concentration in electrolyte during the electrolyzer operation to maintain the electrolyte maximum specific conductivity.

The aim of this work is to develop a methodology for calculating the parameters of feeding water replenishment in the electrolyzer, taking into account the specified alkali concentrations and the real changes of electrolyte volume as well as clarification of the electrolyte electrochemical properties to improve the electrolyzer design.

\section{Selected model and calculation methodology}

The electrolysis process takes place under variable concentration of alkali in the electrolyte if water consumed from the electrolyte is periodically dosed replenishes.
When using an aqueous solution of $\mathrm{KOH}$, it causes changing the electrolyte specific electrical conductivity (Fig. 1) and as a result affects the energy consumption for hydrogen and oxygen generation.

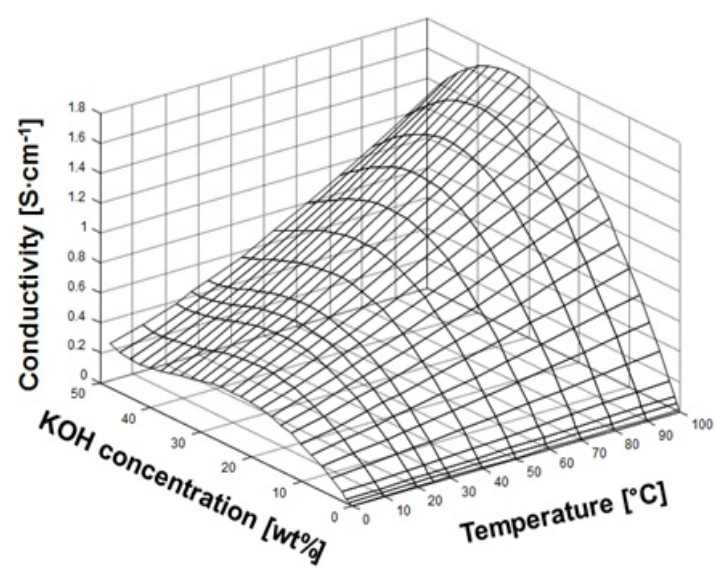

Figure 1. The specific electrical conductivity of $\mathrm{KOH}$ water solutions [16]

The water volume in the initial electrolyte can be conditionally divided into two components, namely, the technological and consumable volume.

The technological water volume is the technologically necessary minimum water volume that ensures the electrolyzer operation, i.e. the electrolysis process itself.

The consumable water volume is water decomposed during the electrolysis process to obtain hydrogen and oxygen during the electrolyzer operation without refilling.

Then the water mass in the electrolyte is

$$
\mathrm{m}_{\mathrm{w}}=\mathrm{m}_{\mathrm{wt}}+\mathrm{m}_{\mathrm{wcons}}=\left(\mathrm{V}_{\mathrm{wt}}+\mathrm{V}_{\mathrm{wcons}}\right) \cdot \rho_{\mathrm{w}},
$$

where $m_{w}$ is the water mass in the electrolyte; $\mathrm{m}_{\mathrm{wt}}$ is the mass of the technological water volume in the electrolyte; $m_{\text {wcons }}$ is the mass of 
the consumable water volume in the electrolyte; $\mathrm{V}_{\mathrm{wt}}$ is the volume of the technological water in the electrolyte; $V_{\text {wcons }}$ is the consumable volume of water in the electrolyte; $\rho_{\mathrm{w}}$ is water density.

The mass of electrolyte filling the electrolyzer initially, taking into account the equation (1), is determined as

$\mathrm{m}_{\mathrm{el}}=\mathrm{m}_{\mathrm{w}}+\mathrm{m}_{\kappa O H}=\left(\mathrm{V}_{\mathrm{wt}}+\mathrm{V}_{\mathrm{wcons}}\right) \cdot \rho_{\mathrm{w}}+\mathrm{m}_{\kappa O H},(2)$

where: $m_{\mathrm{el}}$ is the mass of the electrolyte in the electrolyzer; $\mathrm{m}_{\mathrm{KOH}}$ is the mass of $\mathrm{KOH}$ in the electrolyte.

When $\mathrm{KOH}$ is dissolved in water, the volume of the electrolyte is equal to water volume. Basing on this condition and taking into account the equations (1) and (2), we can write

$$
\mathrm{V}_{\mathrm{el}}=\mathrm{V}_{\mathrm{wt}}+\mathrm{V}_{\mathrm{wcons}} \text {, }
$$

where $\mathrm{V}_{\mathrm{el}}$ is the electrolyte volume in the electrolyzer.

The alkali concentration in electrolyte is defined as

$$
\mathrm{C}_{\mathrm{KOH}}=\frac{\mathrm{m}_{\mathrm{KOH}}}{\mathrm{m}_{\mathrm{eI}}},
$$

where $\mathrm{C}_{\mathrm{KOH}}$ is $\mathrm{KOH}$ concentration in the electrolyte.

From the equations (1), (2) and (4) we obtain

$$
\mathrm{m}_{\mathrm{el}}=\frac{\mathrm{m}_{\mathrm{W}}}{1-\mathrm{c}_{\mathrm{KOH}}}=\frac{\mathrm{m}_{\mathrm{Wt}}+\mathrm{m}_{\mathrm{Wcons}}}{1-\mathrm{C}_{\mathrm{KOH}}} .
$$

Under electrolysis process with periodic dosed feed water replenishing, the $\mathrm{KOH}$ concentration in the electrolyte changes from its minimum value $\mathrm{C}_{\min }$ (at the initial moment after water adding) to the maximum value $\mathrm{C}_{\max }$ (after entire consumption of consumable water).

In this case, the $\mathrm{KOH}$ mass remains practically constant, but the water mass in the electrolyte decreases to the mass of the technological water $-\mathrm{m}_{\mathrm{wt}}$. Therefore, taking into account the equation (5), the mass of the technological part of electrolyte is determined as

$$
\mathrm{m}_{\mathrm{el} . \mathrm{t}}=\frac{\mathrm{m}_{\mathrm{wt}}}{1-\mathrm{c}_{\max }} .
$$

where: $m_{\text {el.t }}$ is the mass of the technological part of electrolyte; $\mathrm{C}_{\max }$ is the $\mathrm{KOH}$ concentration in the electrolyte after entire consumption of the consumable part of water.

Then, taking into account the equation (6), the $\mathrm{KOH}$ mass in the electrolyte is

$$
\mathrm{m}_{\mathrm{KOH}}=\mathrm{m}_{\mathrm{el.} . \mathrm{t}} \cdot \mathrm{C}_{\max }=\mathrm{m}_{\mathrm{wt}} \frac{\mathrm{c}_{\max }}{1-\mathrm{c}_{\max }} .
$$

As it is following from the equations (1), (2), (5) and (7), and also taking into account the $\mathrm{KOH}$ initial concentration in the electrolyte, we obtain

$$
\mathrm{m}_{\mathrm{el}}=\frac{\mathrm{m}_{\mathrm{Wt}}+\mathrm{m}_{\mathrm{Ws}} \mathrm{ms}}{1-\mathrm{c}_{\min }}
$$

$$
\mathrm{m}_{\mathrm{el}}=\mathrm{m}_{\mathrm{wt}}\left(1+\frac{\mathrm{G}_{\max }}{1-\mathrm{G}_{\max }}\right)+\mathrm{m}_{\mathrm{wcons}},
$$

where: $\mathrm{C}_{\min }-$ is the $\mathrm{KOH}$ concentration in the electrolyte at the initial moment after water adding.

From the system of equations (8), we determine the mass of the consumable part of water in the electrolyte composition

$$
\mathrm{m}_{\mathrm{wcons}}=\mathrm{m}_{\mathrm{wt}} \cdot \frac{1+\frac{\mathrm{C}_{\max }}{1 C_{\max }}-\frac{1}{1} \mathrm{C}_{\min }}{\frac{1}{1-\mathrm{C}_{\min }}-1}
$$

or 


$$
\mathrm{m}_{\mathrm{wcons}}=\mathrm{m}_{\mathrm{wt}} \cdot \mathrm{K}_{\Delta \mathrm{C}} \text {, }
$$

where: $\quad K_{\Delta C}=\frac{1+\frac{C_{\max }}{1-C_{\max }}-\frac{1}{1-C_{\min }}}{\frac{1}{1-C_{\min }}-1}$ is the

coefficient taking into account the change of the alkali concentration in the electrolyte during electrolysis.

From the equation (10) we can determine the volume of the consumable part of water in the electrolyte composition

$$
\mathrm{V}_{\mathrm{wcons}}=\mathrm{V}_{\mathrm{wt}} \cdot \mathrm{K}_{\Delta \mathrm{C}} \text {. }
$$

Taking into account the equations (3) and (11), the volume of the electrolyte Vel with minimum $\mathrm{KOH}$ concentration under initial filling the electrolyzer, is determined as

$$
\mathrm{V}_{\mathrm{el}}=\mathrm{V}_{\mathrm{wt}}\left(1+\mathrm{K}_{\Delta \mathrm{C}}\right) \text {. }
$$

The efficiency of an electrolyzer as to hydrogen is determined by its technical possibilities and construction. And the need of feed water for the electrolyzer is determined by its productivity. The time of consuming the consumable part of water in the electrolyte under electrolysis process can be calculated by the formula

$$
\tau_{\mathrm{wcons}}=\frac{\mathrm{m}_{\text {wcons }}}{\mathrm{p}_{\mathrm{HIs}} \cdot \gamma_{\text {fons }}},
$$

where: $\tau_{\text {wcons }}$ is the time of consuming the consumable part of the water in the electrolyte; $\mathrm{P}_{\mathrm{H} 2}$ is the electrolyzer hydrogen productivity; $\gamma_{\text {cons }}$ is the consumption of feed water to obtain $1 \mathrm{~m}^{3}$ of hydrogen.

We can determine the $\mathrm{KOH}$ current concentration in the electrolyte during decomposing the consumable part of water under electrolysis on the base of the equation system (8) and the formula (13) changing $C_{\max }$ on to $\mathrm{C}_{i}\left(\mathrm{C}_{\min } \leq \mathrm{C}_{i} \leq \mathrm{C}_{\max }\right)$ and $\tau_{\mathrm{wcons}}$ on to $\tau_{i}$ $\left(0 \leq \tau_{i} \leq \tau_{\text {wcons }}\right)$

$$
\mathrm{C}_{i}=\frac{1}{\frac{\mathrm{m}_{\mathrm{Wt}}}{\left(\mathrm{m}_{\mathrm{Wt}}+\tau_{\mathrm{z}}-\mathrm{P}_{\mathrm{Hz}} \cdot \gamma_{\text {cons }}\right) \cdot\left(\frac{1}{1-\mathrm{C}_{\min }}-1\right)}+1},
$$

where $\mathrm{C}_{\mathrm{i}}$ is the $\mathrm{KOH}$ current concentration in the electrolyte during decomposing of the consumable part of water; $\tau_{\mathrm{i}}$ is the current time of this water decomposing under electrolysis.

These calculations give the possibility for improving the existing electrolysers to increase their efficiency as well as for developing the new highly effective electrolyzers.

To ensure the electrolyzer specified operational parameters, one of the possible calculation algorithms is the following:

1) set the limiting values $C_{\min }$ and $C_{\max }$; of the $\mathrm{KOH}$ concentration in the electrolyte based on the effective range of changes in the electrolyte specific electrical conductivity [16, 17] and taking into account the temperature regime;

2) set the required amount of the technological part of water in the electrolyte composition $\left(\mathrm{m}_{\mathrm{wt})}\right.$ based on the electrolyzer design;

3) determine the amount of the consumable part of water in the electrolyte composition ( $\mathrm{m}_{\mathrm{wcons}}$ ) using the dependence (10);

4) determine the volume of electrolyte filling the electrolyzer initially by the dependence (12); 
5) the volume of the electrolyte determines the mass-dimensional parameters and the layout of the electrolyzer to be developed;

6) determine the time of consuming the consumable part of water ( $\tau_{\text {wcons }}$ ) and specify the periodicity of feed water topping up based on the amount the consumable part of water ( $\tau_{\text {wcons) }}$ and given electrolyzer hydrogen productivity $\left(\mathrm{P}_{\mathrm{H} 2}\right)$ by the relationship (13).

Other calculation algorithms are possible depending on the given parameters of the electrolyzer. The described technique is also applicable to an electrolyte made on the base of an aqueous $\mathrm{NaOH}$ solution when using [17].

\section{Results and their discussion}

The regulated frequency of topping up the feed water can be set based on the duration of consuming the consumable part of water in the electrolyte and then can be used this data for the electrolyzer control system.

The obtained calculated dependencies make it possible to ensure the specified energyefficient limits for changing the $\mathrm{KOH}$ concentration in the electrolyte during the electrolyser operation. With increasing the $\mathrm{KOH}$ concentration in the electrolyte $(>40 \%)$, its specific electrical conductivity initially increases rapidly and then slows down (Fig. 1).

This character of changing the electrolyte specific electrical conductivity with increasing the alkali concentration can be explained by a decrease of ions mobility in the concentrated solutions due to an increase in viscosity and due to the interaction of the charged ions resulting in inhibition of their movement. The electrical conductivity of an aqueous $\mathrm{KOH}$ solution also increases with increasing temperature. For each temperature, the electrical conductivity passes a maximum with an increase in the $\mathrm{KOH}$ concentration $[16,17]$.

In the range of $\mathrm{KOH}$ optimal concentrations $(28-33 \%)$, the electrolyte resistivity changes insignificantly with a change in the alkali concentration. Therefore, some deviations from the optimum do not cause a noticeable increase in voltage losses to overcome the electrolyte ohmic resistance. When choosing the alkali concentration in the electrolyte, one should also take into account an increase in the corrosion rate of electrolyzer parts with an increase in the concentration of alkali, which, in turn, significantly affects the trouble-free operation and operating costs.

Application of the obtained dependencies for operating electrolysers with periodic replenishment of feed water makes it possible: - to analyze the specific electrical conductivity of the electrolyte based on the initial and final (before water adding) $\mathrm{KOH}$ concentrations; - to calculate the parameters of water topping up, taking into account the specified $\mathrm{KOH}$ concentrations and real changes in the volume of electrolyte during electrolysis; - as well as to correct the automatic control modes of this process. 
The sequence regime of operation of the developed in the IPMash NAS of Ukraine membrane-less high-pressure electrolysis plants [15] involves the periodic dosed replenishment of feed water consumed from the electrolyte for hydrogen and oxygen generation.

Due to the need to ensure the electrolyte maximum specific electrical conductivity and taking into account the electrolyzer's design features, the range of $\mathrm{KOH}$ concentration changes in the electrolyte was selected $25-30 \%$. And the coefficient, which takes into account the alkali concentration change in the electrolyte during electrolysis, is $\mathrm{K}_{\Delta \mathrm{C}}=0.286$.

Table 1 shows the operational parameters of the electrolyte under water electrolysis in the electrolyzers developed in the IPMash NAS of Ukraine. Table 1 shows also the maximum estimated time of consuming the consumable part of the water from the electrolyte, $\tau_{\text {wcons. }}$ This time determines the periodicity of feed water refilling that is multiple to filling the standard cylinders of $0.04 \mathrm{~m}^{3}$ capacity under the maximum pressure of $14.7 \mathrm{MPa}$.

Table 1. Operational parameters of the electrolyte for the high pressure electrolyzers developed at the IPMash NAS of Ukraine.

\begin{tabular}{|c|c|c|c|c|c|c|c|c|}
\hline Electrolyzer & $\begin{array}{l}\text { Рнг, } \\
\mathrm{m}^{3} / \mathrm{h}\end{array}$ & $\begin{array}{c}\mathrm{V}_{\mathrm{el}}, \\
l\end{array}$ & $\begin{array}{l}\mathrm{m}_{\mathrm{wt}} \\
\mathrm{kg}\end{array}$ & $\begin{array}{c}\mathrm{m}_{\text {weons }} \\
\mathrm{kg}\end{array}$ & $\mathrm{C}_{\min }$ & $\mathrm{C}_{\max }$ & $\begin{array}{l}\gamma \text { cons, } \\
\mathrm{kg} / \mathrm{m}^{3}\end{array}$ & $\begin{array}{c}\tau_{\text {wcons }} \\
h\end{array}$ \\
\hline EHP 1.0-150 & 1.0 & 182.6 & 142.0 & 40.6 & \multirow{2}{*}{0.25} & \multirow{2}{*}{0.30} & \multirow{2}{*}{0.82} & 49.5 \\
\hline EHP $0.5-150$ & 0.5 & 91.3 & 71.0 & 20.3 & & & & 49.5 \\
\hline
\end{tabular}

Our high-pressure electrolyzers are of modular design [15]. It provides the ability for increasing their productivity by increasing the number of modules with the identity of the electrolysis process. This stipulate for the identical duration of consumable water consumption period, $\tau_{\text {wcons, }}$ in EHP 1.0-150 and EHP 0.5-150 (table 1) and the identical change of $\mathrm{KOH}$ current concentration in the electrolyte (Fig. 2). The technical solutions of the electrolyzer design were tested under creating the different performance electrolyzers. Such electrolyzers can be adapted to operate in combination with the autonomous power plants feeding from the renewable energy sources.

Figure 2 shows the calculated change of $\mathrm{KOH}$ current concentration in the EHP 1.0-150 and EHP 0.5-150 during decomposing the consumable part of water under condition of the constant electrolyzer productivity by hydrogen, $\mathrm{P}_{\mathrm{H} 2}$.

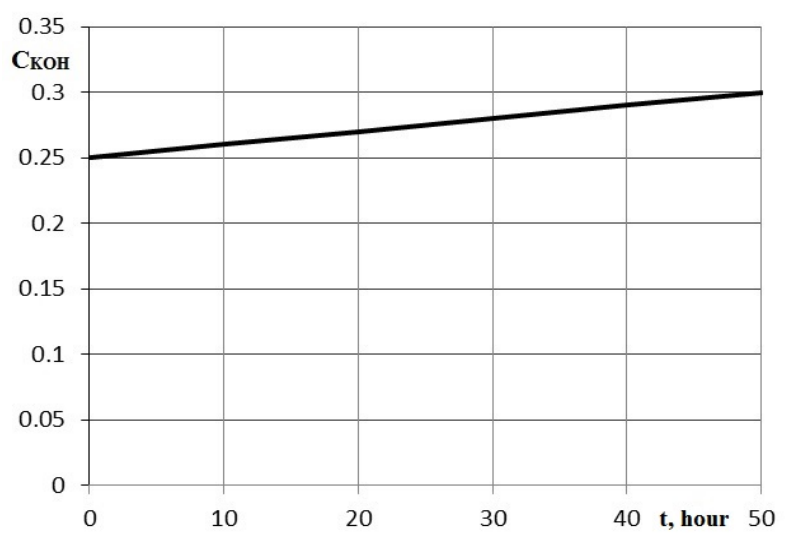

Figure 2. Change of $\mathrm{KOH}$ current concentration in the EHP 1.0-150 and EHP 0.5-150 during decomposing the consumable part of water

Thus, the proposed dependences make it possible to increase the efficiency of the electrolysis process by reducing energy consumption when ensuring the optimal specific 
electrical conductivity of the electrolyte at a variable alkali concentration.

\section{Conclusions}

The electrolysis process takes place under variable concentration of alkali in the electrolyte if water consumed from the electrolyte is periodically dosed replenishes. When using an aqueous solution of $\mathrm{KOH}$, it causes changing the electrolyte specific electrical conductivity (Fig. 1) and as a result affects the energy consumption for hydrogen and oxygen generation.

The proposed dependencies and the methodology developed on their basis give the possibility for:

- analyzing the efficiency of the applied electrolytes at variable alkali concentration taking into account the specific electrical conductivity of the electrolyte;

- reducing energy consumption during electrolysis using the optimal range of changes in the specific electrical conductivity of the electrolyte by choosing the limit values of the alkali concentration in the electrolyte;

- taking into account the specified operating parameters under stage of electrolyzer developing.

When we ensure the maximum specific electrical conductivity of the electrolyte under electrolysis process, the optimal range of $\mathrm{KOH}$ concentration changes is of $28-33 \%$, with $\mathrm{K}_{\Delta \mathrm{C}}=$ 0.267 .

\section{References}

[1] O. Schmidt, A. Gambhir, I. Staffell, A. Hawkes, J. Nelson, S. Few. Future cost and performance of water electrolysis: An expert elicitation study. Int. J. of Hydrogen Energy. 2017. Vol. 42. № 52. P. 30470-30492. https://www.sciencedirect.com/science/article/pii/S03603 19917339435.

[2] Foteini M. Sapountzi, Jose M. Gracia, C.J. Weststrate, Hans O.A. Fredriksson,

J.W. Niemantsverdriet. Electrocatalysts for the generation of hydrogen, oxygen and synthesis gas. Progress in Energy and Combustion Science. 2017. № 58. P. 1-35. https://www.sciencedirect.com/journal/progressin-energy-and-combustion-science/vol/58/suppl/C

[3] Feichen Yang, Myung Jun Kim, Micah Brown, Benjamin J. Wiley. Alkaline Water Electrolysis at 25 A $\cdot \mathrm{cm}^{-2}$ with a Microfibrous Flow-through Electrode. Advanced Energy Materials. 2020. vol. 10 (25). https://doi.org/10.1002/aenm.202001174.

[4] Hamish Andrew Miller, Karel Bouzek, Jaromir Hnat, Stefan Loos, Christian Immanuel Bernäcker, Thomas Weißgärber, Lars Röntzsch, Jochen Meier-Haack. Green hydrogen from anion exchange membrane water electrolysis: a review of recent developments in critical materials and operating conditions. Sustainable Energy \& Fuels. 2020. Vol 4. P. 2114-2133. DOI: 10.1039/C9SE01240K.

[5] Yoo Sei Park, Juchan Yang, Jongmin Lee, Myeong Je Jang, Jaehoon Jeong, Woo-Sung Choi, Yangdo Kim, Yadong Yin, Min Ho Seo, Zhongwei Chen, Sung Mook Choi. Superior performance of anion exchange membrane water electrolyzer: Ensemble of producing oxygen vacancies and controlling mass transfer resistance. Applied Catalysis B: Environmental. 2020. Vol. 278 (119276). https://doi.org/10.1016/j.apcatb.2020.119276.

[6] Elena Rozzi, Francesco Demetrio Minuto, Andrea Lanzini, Pierluigi Leone. Green Synthetic Fuels: Renewable Routes for the Conversion of Non-Fossil Feedstocks into Gaseous Fuels and Their End Uses. Energies. 2020. vol. 13 (2), (420). https://doi.org/10.3390/en13020420. 
[7] Maria Ronda-Lloret, Gadi Rothenberg, N. Raveendran

Shiju. A Critical Look at Direct Catalytic Hydrogenation of Carbon Dioxide to Olefins, ChemSusChem. 2019.

Vol. 12 (17). P. 3896-3914 https://doi.org/10.1002/ cssc. 201900915.

[8] Reza Abbasi, Brian P. Setzler, Saisai Lin, Junhua Wang, Yun Zhao, Hui Xu, Bryan Pivovar, Boyuan Tian, Xi Chen, Gang Wu, Yushan Yan. A Roadmap to Low-Cost. Hydrogen with Hydroxide Exchange Membrane Electrolyzers. Advanced Materials. 2019. Vol. 31 (31). DOI: 10.1002/adma.201805876.

[9] Antonio Valente, Diego Iribarren, Javier Dufour. End of life of fuel cells and hydrogen products: From technologies to strategies, International Journal of Hydrogen Energy, 2019. https://doi.org/10.1016/j.ijhydene.2019.01.110.

[10] Alejandro N. Colli, Hubert H. Girault, Alberto Battistel. Non-Precious Electrodes for Practical Alkaline Water Electrolysis. Materials. 2019. Vol. 12, 8, (1336). doi: $\underline{10.3390 / \mathrm{ma1} 2081336 .}$

[11] Zengcai Liu, Syed Dawar Sajjad, Yan Gao, Hongzhou Yang, Jerry J. Kaczur, Richard I. Masel. The effect of membrane on an alkaline water electrolyzer. International Journal of Hydrogen Energy. 2017. Vol. 42, 50. P. 29661-29665.

https://doi.org/10.1016/j.ijhydene.2017.10.050.

[12] Yakimenko L. M., Modylevskaya, I. D., \& Tkachik, Z. A. Electrolysis of water. Moscow: Khimiya, 1970. 264 p. (in Russian).

[13] D.Yu. Hamburg, N.F. Dubovkin. Hydrogen. Properties, receipt, storage, transportation, application. - M.: Chemistry, 1989. $672 \mathrm{p}$.

[14] Solovey V.V., Khiem N.T., Zipunnikov M.M., Shevchenko A.A. Improvement of the membrane-less electrolysis technology for hydrogen and oxygen generation. French-Ukrainian J. Chemistry. 2018. Vol. 6. № 2. P. 73-79. https://doi.org/10.17721/fujcV6I2P73-79.

[15] Solovey V.V., Kotenko A.L., $\quad$ Vorobjova I.O., Shevchenko A.A., \& Zipunnikov M.M. Basic Operation Principles and Control Algorithm for a High-pressure
Membrane-less Electrolyser. Journal of Mechanical Engineering. 2018. Vol. 21. № 4, pp. 57-63. https://doi.org/10.15407/pmach2018.04.057.

[16] R.J. Gilliam, J.W. Graydon, D.W. Kirk, S.J. Thorpe. A review of specific conductivities of potassium hydroxide solutions for various concentrations and temperatures. Int. J. Hydrogen Energy. 2007. Vol. 32. № 3. P. 359-364. ttps://www.sciencedirect.com/science/ article/abs/pii/S0360319906005428.

[17] D. Le Bideau, Ph. Mandin, M. Kim, M. Sellier. Review of necessary thermophysical properties and their sensivities with temperature and electrolyte mass fractions for alkaline water electrolysis multiphysics modeling. Int. J. Hydrogen Energy. 2019. Vol. 44. № 10. P. 4553-4569. https://www.sciencedirect.com/science/article/abs/pii/ 